\title{
A DESCRIPTIVE RETROSPECTIVE HOSPITAL BASED REVIEW OF CHEST $X$ RAY FINDINGS OF SRI LANKAN COVID 19 PATIENTS IN A SINGLE CENTRE (NATIONAL INSTITUTE OF INFECTIOUS DISEASE) IN SRI LANKA
}

\author{
Abeywardana $\mathrm{K}^{1}$, De Mel VPRS ${ }^{2}$, Arasalingam $\mathrm{A}^{3}$ \\ ${ }^{1}$ Acting Consultant Radiologist, National Institute of Infectious Diseases, Sri Lanka. \\ ${ }^{2}$ Acting Consultant Radiologist, Colombo East Base Hospital Mulleriyawa, Sri Lanka. \\ ${ }^{3}$ Senior Lecturer in Medicine, Faculty of Medicine, University of Jaffna, Sri Lanka.
}

Keywords : Imaging in COVID, Chest X-ray, CXR, Sri Lanka, prognostication score using chest $X$ rays.

Corresponding Author: Abeywardana $K^{1}$

Copyright: Abeywardana $K^{1}$

https://orcid.org/0000-0002-1039-8951

\begin{abstract}
COVID-19 ravaging through the world and third world countries with limited resources envisages a cost effective and feasible imaging and prognostication score. We aim to develop a prognostication score based on the first chest X-ray to assess deterioration and need to transfer to specialized treatment units should the wave of COVID - 19 surge to higher levels.
\end{abstract}

A retrospective study reviewing chest $X$ rays and case notes were analyzed by two radiologists and in case of disagreement a third radiologist was consulted. The lung changes were classified using Fleischner Society Glossary of Terms for Thoracic Imaging. Each lung was divided into 4 zones and a score of 1 given to each affected zone. The total score was used to prognosticate. Of the 146 patients there was a male preponderance. In $26.7 \%$, the initial chest X-rays were abnormal. The peripheral, lower zone and bilateral involvement was more common. The scores of the initial chest X-ray correlated with the severity of the disease. With a sensitivity of $31.6 \%$, chest X-ray is a poor screening investigation but with a specificity of $96.2 \%$ it can be used to prognosticate the outcome and monitor the progression of the disease.

\section{Introduction}

COVID-19 caused by severe acute respiratory syndrome coronavirus 2 (SARS-CoV-2) originated in Wuhan, China in December 2019. The World Health Organization declared COVID-19 a public health emergency of international concern in January 2020 and a pandemic on $11^{\text {th }}$ March 2020. Sri Lanka's first confirmed case was a 44-year-old Chinese female tourist from the Hubei Province in China. The first confirmed reverse transcription 
Polymerase Chain Reaction (rt PCR) positive Sri Lankan patient was detected on $3^{\text {rd }}$ March 2020.

Computed tomography (CT) of the chest is the ideal imaging modality. Chest X-ray (CXR) is the preferred mode of imaging in low and low-middle income countries considering the availability of infrastructure, proper personal protective equipment and carrying on uninterrupted non-COVID related radiological services. Data on the sensitivity and specificity of CXR in the diagnosis of COVID-19 at the beginning of the pandemic was sparse. Globally, testing and imaging posed challenges even to the first world countries. With the surge in COVID -19 cases worldwide, Sri Lanka had to prepare for a possible escalation of cases with available resources. CXR is the readily accessible imaging modality in Sri Lanka and available in all levels of care from primary to tertiary care centres.

Based on available studies chest imaging findings are non-specific, however bilateral, peripheral and basal changes were more common ${ }^{(1)}$. CXR is normal in early and mild disease. Wang HYF et al studied 64 patients in 4 hospitals in Hongkong and concluded that 69\% had an abnormal CXR at admission and 80\% developed abnormalities during hospital stay with the more extensive changes occurring 10 to 12 days after admission. The commonest findings were air space opacities which were either consolidations or ground glass opacifications. The findings were predominantly bilateral, peripheral and in the lower zones of the lung field ${ }^{(2)}$. These findings were further supported by the update by Rodrigues JC et.al ${ }^{(3)}$. Wang HYF et al studied 64 COVID-19 patients in Hongkong and concluded the sensitivity was $69 \%$ with peripheral, lower zone and bilateral lesions being the commonest ${ }^{(2)}$. There are fewer studies on CXR finding compared to other imaging modalities. A highly powered study has not been carried out. The conclusions cannot be generalized as the studies are not highly powered. Considering CT chest as the gold standard the patients should undergo CT imaging at the same time as the CXR for a conclusive result. However, addressing these gaps has many technical and logistic implications and was not addressed in some of these studies.

\section{Aim and objectives:}

\section{Aim:}

Developing a simple scoring system that would be used by a junior medical officer or even a paramedic (with minimal training in radiology) in charge of COVID treatment and quarantine centres in Sri Lanka. Our scoring system would be useful to detect patients with worsening lung signs to be transferred to specialized centres.

\section{Research Objective 1:}

To study the demographic pattern of rt-PCR confirmed COVID-19 positive Sri Lankan patients admitted to the National Institute of Infectious Diseases (NIID) in Sri Lanka.

\section{Research Objective 2:}

To study the pattern of lung changes on the first CXR done on COVID positive Sri Lankan patients after admission to NIID. 


\section{Research Objective 3:}

To develop a scoring system based on the findings on the first CXR to prognosticate the evolution and outcome of the disease.

\section{Materials and methods}

We carried out a retrospective, descriptive, hospital-based case note and CXR review at the Radiology Department and the COVID treating wards of the National Institute of Infectious Diseases (NIID), Angoda, Sri Lanka on all Sri Lankan patients above the age of 12 years, with a laboratory confirmed rt-PCR positive COVID-19 infection who have undergone a chest X-ray (CXR). The study period was from 11th March to 31st May 2020. Data was collected using a data extraction form and the definition of CXR findings were based on the Fleischner glossary. The case definitions were as per the WHO case definitions. We set up a scoring system where a score was given to all abnormal CXR depending on the extent of lung involvement in the initial CXR with a total score of 8. Demographic data and patient outcome were obtained from the hospital records and the first available CXRs were reported independently by two radiologists and in the event of disagreement, expert opinion was sought from an independent third radiologist.

\section{Image processing and analysis:}

The X-rays were obtained using the same mobile X-ray machine (GE Optima XR 200 AMX) as inward procedures by two radiographers and developed using the same Computed Radiography (CR) system (Fugi Prima T2). Personal Protective Equipment was used by radiographer who performed the X-ray. One radiographer was in contact with the patient while the other radiographer was clean to prevent cross contamination.

The chest X-rays were reported on the $\mathrm{CR}$ viewing console and double reported independently by two radiologists.

\section{Scoring system:}

Lungs were divided into upper and lower zones by an arbitrary line drawn horizontally at the hilum and further divided into perihilar (central) and peripheral by an arbitrary line halfway between the hilum and chest wall. Hence each lung was divided into 4 zones, 8 in total.

Each lung was assessed for Ground Glass Opacity (GGO) and consolidation, according to Fleisher glossary. GGO was considered as hazy increased opacification of lung field with the preservation of bronchial and vascular markings. Consolidations was considered as homogenous increase in pulmonary opacity that obscures the vessel and bronchial walls. Each zone affected by either Ground Glass Opacity or consolidation was given a score of 1 and each abnormal chest X-ray was given a total score out of 8 . Patient outcome during the study period was recorded as death, admission to intensive care unit, complete recovery and discharge, or still receiving inward care at time of study completion. 


\section{Statistics:}

Data was analyzed using SPSS version 26. The statistical analysis was carried out using the SPSS version 26. The continuous variables were expressed as a mean with standard deviations and the discrete variables were expressed as percentages.

\section{Results}

Main Findings related to Objective 1:

A total of 146 CXRs were analyzed. Table 1 describes the demographic data.

Table 1: Demographic data $(\mathrm{n}=146)$.

\begin{tabular}{|l|l|}
\hline Age (mean) & $\begin{array}{l}42.51+/-13.78 \text { years } \\
\text { (range 14 to 85 years) }\end{array}$ \\
\hline $\begin{array}{l}\text { Duration of Hospital } \\
\text { Stay }\end{array}$ & $\begin{array}{l}23.5+/-15.22 \text { days } \\
\text { (range 3 -67 days) }\end{array}$ \\
\hline $\begin{array}{l}\text { Day of first CXR since } \\
\text { onset of symptoms }\end{array}$ & $\begin{array}{l}7.8+/-6.23 \text { days } \\
\text { (range 1-39 days) }\end{array}$ \\
\hline Gender & $\begin{array}{l}\text { Males }=96(65.8 \%) \\
\text { Females }=50(34.2 \%)\end{array}$ \\
\hline $\begin{array}{l}\text { Clinical condition on } \\
\text { admission }\end{array}$ & $\begin{array}{l}\text { Symptomatic }=120(82.2 \%) \\
\text { Asymptomatic }=26(17.8 \%)\end{array}$ \\
\hline First CXR findings & $\begin{array}{l}\text { Normal }=107(73.3 \%) \\
\text { Abnormal }=39(26.7 \%)\end{array}$ \\
\hline CXR projections & $\begin{array}{l}\text { Anteroposterior }=95(65.1 \%) \\
\text { Posteroanterior }=51(26.7 \%)\end{array}$ \\
\hline
\end{tabular}

Main Findings related to Objective 2:

Of the 146 rt-PCR positive COVID 19 patients 39 (26.7\%) had an abnormal first CXR. The sensitivity of first CXR in Sri Lankan COVID patients was $31.6 \%$, and the specificity was $96.2 \%$.

Table 2: Demographic pattern of those with an abnormal first CXR

\begin{tabular}{|l|l|}
\hline Age (Mean) & $\begin{array}{l}50.21+/-15.28 \text { years } \\
\text { (range 23 }-85 \text { years) }\end{array}$ \\
\hline $\begin{array}{l}\text { Day of first CXR since } \\
\text { onset of symptoms }\end{array}$ & $\begin{array}{l}7.03+/-3.98 \text { days } \\
\text { (range 1-23 days) }\end{array}$ \\
\hline $\begin{array}{l}\text { Percentage of abnormal } \\
\text { CXR }\end{array}$ & $39 / 146(26.7 \%)$ \\
\hline Gender & $\begin{array}{l}\text { Males }=27(69.2 \%) \\
\text { Females }=12(30.8 \%)\end{array}$ \\
\hline $\begin{array}{l}\text { Clinical condition on } \\
\text { admission }\end{array}$ & $\begin{array}{l}\text { Symptomatic }=38(97.4 \%) \\
\text { Asymptomatic }=1(2.6 \%)\end{array}$ \\
\hline $\begin{array}{l}\text { ICU admissions in those } \\
\text { with abnormal CXR }\end{array}$ & $16 / 39(41 \%)$ \\
\hline
\end{tabular}


We further analyzed the positive CXR including providing a scoring system for the CXR. Of those with a positive CXR, 4 died (10.3\%), 25 (64.1\%) had a complete recovery and 10 $(25.6 \%)$ were still being treated in the hospital on the date the study was concluded.

Table 3: Symptomatic first CXR $(n=39)$ (lung fields $=60$; included are 18 unilateral $+(21 * 2)$ 42 bilateral involvement.

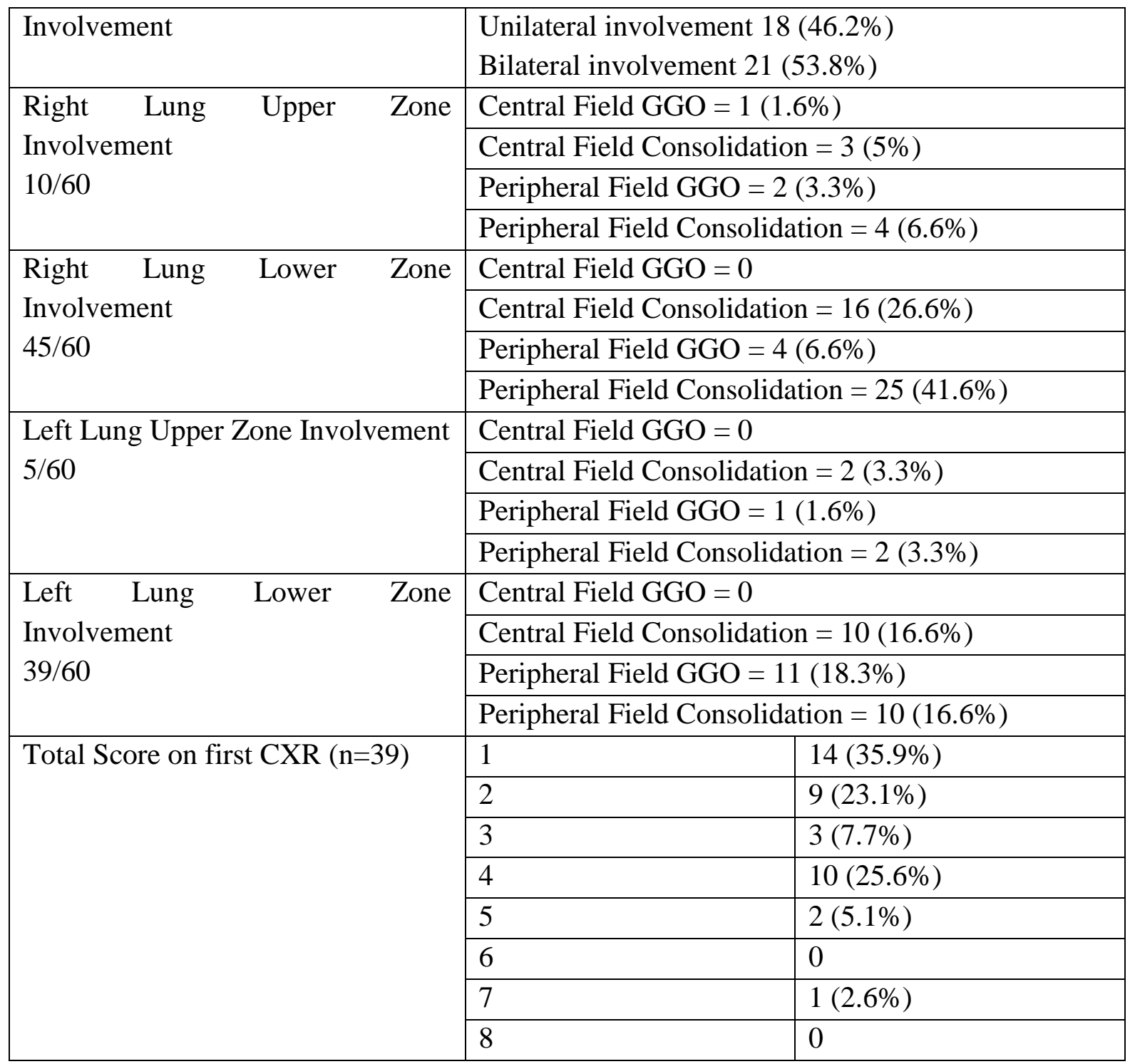

Main Findings related to Objective 3:

We further analyzed the outcomes namely - ICU admissions, complete recovery and death as on the last day of data collection based on the scores of the first CXR. 
Table 4: Outcomes based on total scores of first CXR

\begin{tabular}{|c|c|c|c|}
\hline \multicolumn{4}{|c|}{ Abnormal First Chest X-ray $(n=39)$} \\
\hline $\begin{array}{l}\text { Total } \\
\text { Score } \\
\text { (n= total } \\
\text { number) }\end{array}$ & $\begin{array}{l}\text { ICU } \\
\text { admission }\end{array}$ & $\begin{array}{l}\text { Complete } \\
\text { recovery }\end{array}$ & Death \\
\hline $1(n=14)$ & $2(14.2 \%)$ & $\begin{array}{l}10 \\
(71.4 \%)\end{array}$ & 0 \\
\hline $2(n=9)$ & $4(44.4 \%)$ & $5(55.5 \%)$ & $\begin{array}{l}1 \\
(11.1 \%)\end{array}$ \\
\hline $3(n=3)$ & $1(33.3 \%)$ & $3(100 \%)$ & 0 \\
\hline $4(n=10)$ & $7(70 \%)$ & $6(60 \%)$ & $1(10 \%)$ \\
\hline $5(n=2)$ & $1(50 \%)$ & $1(50 \%)$ & $1(50 \%)$ \\
\hline $6(n=0)$ & 0 & 0 & 0 \\
\hline $7(n=1)$ & $1(100 \%)$ & $0(0 \%)$ & $1(100 \%)$ \\
\hline $8(\mathrm{n}=0)$ & 0 & 0 & 0 \\
\hline
\end{tabular}

Table 5: Detail Analysis of deaths $(\mathrm{n}=4)$

\begin{tabular}{|l|l|l|l|}
\hline Case & Age & Gender & $\begin{array}{l}\text { First CXR } \\
\text { score }\end{array}$ \\
\hline 1 & 60 & Male & 5 \\
\hline 2 & 48 & Male & 4 \\
\hline 3 & 58 & Male & 2 \\
\hline 4 & 80 & Male & 7 \\
\hline
\end{tabular}

\section{Discussion}

Our study aimed to develop a simple scoring system which would be used for disease prognostication.

\section{Finding 1:}

The mean age of our patients was 42.5 years with a range between 14 to $85 \%$, with a male preponderance. $82 \%$ were symptomatic on admission but only $26.7 \%$ had an abnormal first CXR. The sensitivity of first CXR in Sri Lankan COVID patients was 31.6\%, and the specificity was $96.2 \%$. Compared to other studies the sensitivity of first CXR is low in our population.

Limited number of cases were reported during this initial stage as restrictions were imposed on local and foreign travel and strict quarantine laws were implemented with a view to curtail disease spread. All patients with a positive rt-PCR were admitted to hospital (majority to 
NIID) irrespective of disease severity. There was only contact transmission / cluster spread during this time with no community transmission.

There was no CT scan facility available in the hospital during this time and chest Xray was the main imaging modality. Chest X-rays were only performed on symptomatic patients on request by the treating clinician. Thus, the low sensitivity could be attributed to the admission of patients with mild disease, compatible with previous studies showing that CXR findings can be normal in mild disease ${ }^{(2)}$.

\section{Finding 2:}

Bilateral lung involvement was seen in $53.8 \%$ and peripheral and lower zone involvement was predominant with the right lower zone being the commonest involved. Consolidation was more commonly detected over ground glass opacities. These findings were similar to the other studies.

Similarly in the study conducted by Wang HYF et al in Hongkong ${ }^{(2)}$ on baseline CXR, consolidation was the most common finding (47\%), followed by GGO (33\%). Most had bilateral involvement (50\%) with peripheral involvement $(41 \%)$ and lower zone distribution $(50 \%)$ being the more common locations. Another study by Heshui Shi et al in China ${ }^{(4)}$ where chest CT findings are discussed, the predominant pattern of abnormality observed were bilateral involvement (79\%) with peripheral lung involvement in 54\%, mainly involving the right lower lobes $(27 \%)$. This correlates well with our study results.

\section{Finding 3:}

A score of 4 or above showed higher morbidity with ICU admissions (score $4-70 \%$; score 5 - 50\%; score $7-100 \%$ ). There were no patients with a score of 6 or 8 on initial CXR. 3 out of 4 patients who died had a score of 4 or above (score $5-50 \%$; score $7-100 \%$ ).

HYF Wong et $\mathrm{al}^{(2)}$ concluded that $41 \%$ had mild findings with total severity score of $1-2$, while moderate and severe cases with more extensive lung involvement was seen in $20 \%$ and $8 \%$ of patients, who had severity scores of 3-4 and 5-6, respectively. There was no patient who had a severity score of $>6$ on their baseline CXR.

Findings of our study as well as others showed promising results favorable towards developing a severity score for acute viral pneumonias which would predict disease outcome. The salient features are CXR sensitivity is low and therefore not suitable as a screening method. The specificity was high at $96.2 \%$ and make it a useful investigation for diagnosis and prognostication. Higher severity scores of initial CXRs were associated with worse outcome.

\section{Limitations of our study:}

Major Limitations were the small study sample and lack of standard clinical criteria for performing the initial CXR. CT scan was not available to correlate results. "Normal CXRs" may have GGO missed on plain film. This being our initial study is not highly powered and 
conclusions cannot be generalized. Considering CT chest as the gold standard the patients should undergo CT imaging at the same time as the CXR for a conclusive result.

\section{Implications of the whole study together for the field:}

CXR is a poor screening investigation but is good to prognosticate the outcome and monitor the progression of the disease.

\section{Recommendations:}

A larger study sample is recommended to validate these results with a view for developing a useful severity score index for future viral pneumonia pandemics. We intend to perform the validation of our score in Sri Lankan patients using a larger sample. We also hope to test the validity of this scoring system in quarantine centres and other treatment centres where possible.

\section{Conclusion \& take-home message:}

Our scoring system is promising to be used as a score of severity and prognostication and also to have a precise figure to determine deterioration or improvement of lung signs.

\section{References:}

1. Kanne JP, Little BP, Chung JH, Elicker BM, Ketai LH. Essentials for radiologists on COVID-19: An update - radiology scientific expert panel. Published online February 27 2020.

2. Wong HY, Lam HY, Fong AH, Leung ST, Chin TW, et al. Frequency and Distribution of Chest Radiographic Findings in COVID-19 Positive Patients. Published online March 27 2020.

3. Rodrigues JC, Hare SS, Edey A, Devaraj A, Jacob J, et al. An update on COVID-19 for the radiologist-A British society of Thoracic Imaging statement. Clinical Radiology (2020) 75:323-325. - Published 01 May 2020.

4. Shi XH, Jiang N, Cao $\mathrm{Y}$ et al. Radiological findings from 81 patients with COVID-19 pneumonia in Wuhan, China: a descriptive study. www.thelancet.com/infection Vol 20 April 2020 - Published April 2020. 


\section{Acknowledgements}

Director National Institute of Infectious Diseases, Sri Lanka: Dr. Hasitha Attanayake

Staff of the COVID wards of NIID, Sri Lanka. Dr. Ananda Wijewickrama (Senior Consultant Physician) Dr. Damayanthi Idampitiya, Dr. Eranga Narangoda, Dr. A G S Asiri, Dr.

Sithumini Pahalagamage (Consultant Physicians), medical officers and paramedical staff. Staff of the Department of Radiology NIID, Sri Lanka: Ms. Nimmi Hathurusinghe and Ms. Kaushalya Gunasekera (Radiographers), Mrs. Kanchana (Nursing officer) and other staff. Dr. Vayani Wijesundara Consultant Radiologist, Base Hospital Kiribathgoda, Sri Lanka.

\section{Abbreviations:}

CXR - Chest X-ray

NIID - National Institute of Infectious Diseases

rtPCR - reverse transcription Polymerase Chain Reaction

WHO- World Health Organization

GGO- Ground Glass Opacity

\section{Supplementary Information}

Diagrams:
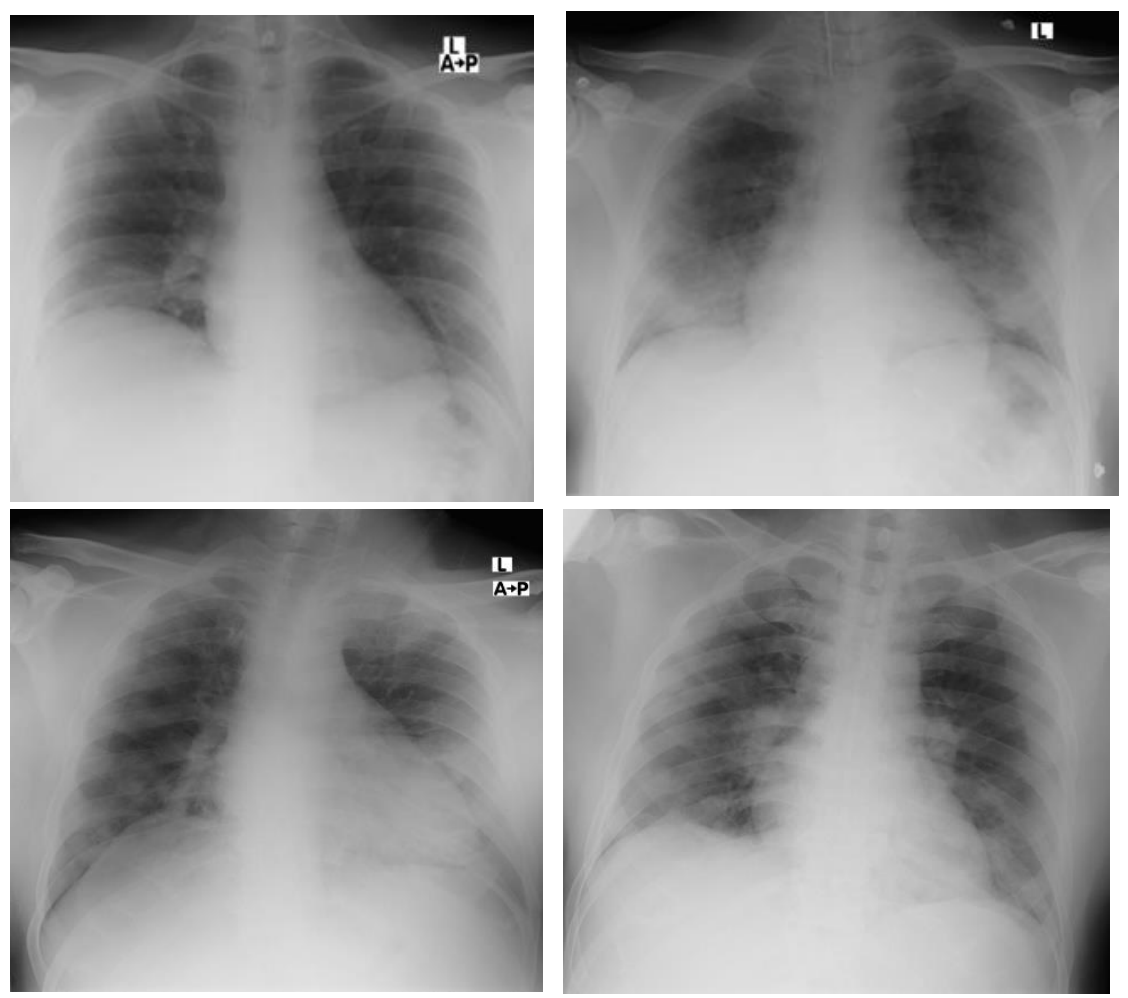

Initial CXRs with varying degrees of lung involvement with ground glass opacities and consolidations.

\section{Conflict of Interest:}

The authors declare no conflict of interest. 